\section{TÀI LIÊU THAM KHẢO}

1. Srivastava K.A., Srivastava1 D.C., Gaur S.C. (2008), Lateral closed wedge osteotomy for cubitus varus deformity.IJO - October - December 2008 / Volume 42 / Issue 4.

2. Roach J.W., Hernandez M.A. (1991). Corrective osteotomy for cubits vanis after Supracondylar fracture. J Paediatr Orthop 1991;14:187-91.

3. Ahmad I., Khan A., Idrees.M ( 2007). Modified French Osteotomy for cubitus varus deformity. Pakistan journal of Surgery, Volume 33, p270-272.
4. Ippolito E., Moneta M.R., D’Arrigo C. (1990). Post-traumatic cubitus varus. J BoneJoint Surg Am. 1990;72(5):757-765.

5. Ranjib K.J., Santosh T., Dhiraj S. (2019).Outcome of Corrective Dome Osteotomy for Cubitus Varus Deformity. Journal of Nobel Medical College,Volume 08, Number 02, Issue 15, July-December 2019, 42-46.

6. Kim H.T., Lee J.S., Yoo C.I.(2005) Management of cubitus varus and valgus. J Bone Joint Surg Am. 2005;87

\title{
ĐẶC ĐIỂM LÂM SÀNG, CHẨN ĐOÁN ĐIỆN VÀ CÁC YẾU TỐ TIÊN LƯỢNG PHỤC HỒI TỔN THƯO'NG THẦN KINH QUAY
}

\section{TÓM TẮT}

Mục tiêu:1) mô tả đặc điểm lâm sàng, chẩn đoán điện ở người bệnh tổn thương thần kinh quay giai đoạn sớm; 2) mồ tả các yếu tố tiên lượng phục hồi ở người bệnh tổn thương thần kinh quay giai đoạn sớm. Đối tượing và phương pháp: Nghiên cứu mồ tả cắt ngang trên 64 người bệnh được chẩn đoán tổn thương thần kinh quay giai đoan sớm tai bênh viên Hữu Nghị Việt Đức từ 1/2020 đển 12/2020. Kết quả: Tổn thương tại cánh tay chiếm $57,8 \%, 29,7 \%$ số ca có hiện tượng nghẽn dẩn truyền thần kinh. Tỷ lệ có phục hồi chức năng thần kinh là $71,9 \%$. Kết luận:Triệu chứng lâm sàng và điện chẩn cơ trong tổn thương dây thần kinh quay rất đa dạng, phụ thuộc vào vị trí, thời gian và hình thái tổn thương. Dây thần kinh quay có tiên lượng phục hồi tốt, có liên quan tới thời gian phát hiện và điều trị, hình thái tổn thương và dấu hiêu trên điền chẩn cớ.

Tư khoá: Điên sinh lý thần kinh, tổn thương thần kinh quay, liệt thẩn kinh quay.

\section{SUMMARY}

\section{CLINICAL, ELECTROPHYSIOLOGY AND THE RECOVERING PROGNOSTIC FACTORS IN RADIAL NERVE PALSY}

Objectives: 1)Describe the clinical and electrophysiology characteristics of the early radial nerve palsy. 2) Describe the recovering prognostic factors in radial nerve palsy. Subjects and method: A cross-sectional descriptive study on 64 patients diagnosed with radial nerve palsy at Viet Duc university Hospital from 1/2020 -12/2020. Results: Injury to the arm accounts for $57.8 \%, 29.7 \%$ of cases

\footnotetext{
${ }^{1}$ Bệnh viện Hữu Nghị Việt Đức

${ }^{2}$ Trường Đại học Y Hà Nội

Chịu trách nhiệm chính: Lê Quốc Việt

Email: leviet11051989@gmail.com

Ngày nhận bài: 24/4/2021

Ngày phản biện khoa học: 18/5/2021

Ngày duyệt bài: 12/6/2021
}

Lê Quốc Việt ${ }^{1}$, Phạm Đức Hiếu ${ }^{1}$, Đồng Ngọc Minh ${ }^{1}$, Nguyễn Anh Tuấn ${ }^{1,2}$ have neurotransmitter obstruction. The rate of neurological rehabilitation is $71.9 \%$. Conclusions:The clinical and electrodiagnostic symptoms of radial nerve injury are variety, depending on the location, duration and morphology of the lesion. The radial palsy nerve has a good prognosis for recovery, related to detection and treatment time, lesion morphology and electromyographic signs.

Key words: Electroneurophysiology, radial injury, radial nerve palsy.

\section{I. ĐĂT VẤN ĐỀ}

Thần kinh quay có đường đi dài, quanh co và đi gần thân xương cánh tay nên thường bị tổn thương. Tổn thương thần kinh quay có thể xảy ra ở bất cứ điểm nào trên đường đi dây thần kinh và nguyên nhân cũng rất khác nhau [1]. Chẩn đoán dựa trên thăm khám lâm sàng, chẩn đoán điện và $X$ - quang để xác định vị trí và mức độ tổn thương. Tổn thương thần kinh chia thành ba loại: mất thực dụng thần kinh (neurapraxia); tổn thương sợi trục (axonotmesis); tổn thương thần kinh (neurotmesis) [2]. Điều tri bảo tồn có thể hiệu quả ở $70 \%$ trường hợp liệt thần kinh quay cao [3].

Phục hồi thần kinh phụ thuộc vào nhiều yếu tố như tuổi, giới, thời gian, phương pháp điều trị, hình thái tổn thương...[4]. Do đó chúng tôi tiến hành nghiên cứu với mục tiêu: 1) Mô tả đặc điểm lâm sàng, chẩn đoán điện ở người bệnh tổn thương thần kinh quay giai đoạn sớm. 2) Mô tả các yếu tố tiên lượng phục hồi ở người bệnh tổn thương thần kinh quay giai đoạn sớm

II. Đốl TƯỢNG VÀ PHƯƠNG PHÁP NGHIÊN CỨU

1. Đối tượng nghiên cứu. Gồm các bệnh nhân bị tổn thương thần kinh quay giai đoạn sớm tại Bệnh viện Hữu Nghị Việt Đức từ 1/2020 $-12 / 2020$. 
Tiêu chuẩn lựa chọn bệnh nhân: Bệnh nhân được chẩn đoán là tổn thương thần kinh quay giai đoạn sớm vào khám và làm điện sinh lý thần kinh cơ tại Bệnh viện Hữu Nghị Việt Đức; Bệnh nhân đồng ý tham gia nghiên cứu.

Tiêu chuẩn loại trừ bệnh nhân: Tổn thương thần kinh quay sau 03 tháng, Bệnh lý thần kinh ngoại biên ở chi trên nằm trong bệnh cảnh của một bệnh lý toàn thân khác; Đau, rối loạn cảm giác vận động do các nguyên nhân đến từ tổn thương hệ thống cơ xương khớp mạch máu; Bệnh nhân không thu thập đây đủ dữ liệu về lâm sàng hoặc điện sinh lý thần kinh cớ; Bệnh nhân có các rối loạn toàn thân nặng khác không cho phép tiến hành đầy đủ thăm dò điện sinh lý thần kinh cớ.

\section{Phương pháp nghiên cứu}

Thiết kế nghiên cứu: Nghiên cứu mô tả cắt ngang.

Chọn mẫu: chọn mẫu thuận tiện, gồm tất cả bệnh nhân được chẩn đoán tổn thương thần kinh quay giai đoạn sớm tại bệnh viện Hữu Nghị Việt Đức trong năm 2020.

\section{Biến số nghiên cứu:}

Nhóm biến số thông tin chung: tuổi, giới, thời gian bị, nguyên nhân thu thập bằng phỏng vấn và điền vào bệnh án nghiên cứu

Nhóm biến số triệu chứng lâm sàng: yếu cơ, teo cơ, rối loạn cảm giác, phản xạ gân xương... thu thập bằng khám lâm sàng và điền vào bệnh án nghiên cứu

Nhóm biến số triệu chứng điện sinh lý thần kinh: biên độ đáp ứng vận động, cảm giác, tốc độ dẫn truyền vận động, cảm giác, điện thế tự phát, đơn vị vận động, kết tập... được thu thập bằng máy đo điện cơ Nihon Kohden Model: MEB9400K và điền vào bệnh án nghiên cứu.
4. Phương pháp phân tích số liệu: Số liệu thu thập sẽ được xử lý trên phần mềm SPSS 16.0. Xử lý số liệu theo phương pháp thống kê y học.

\section{5. Đạo đức nghiên cứu}

Bệnh nhân được giải thích về mục tiêu nghiên cứu và bệnh nhân đồng ý tham gia

nghiên cứu. Thông tin của bệnh nhân được mã hoá và được bảo mật. Bệnh nhân có quyền dừng tham gia nghiên cứu bất kỳ thời điểm nào mà không bị phân biệt trong quá trình chẩn đoán và điều trị.

\section{KẾT QUẢ NGHIÊN CỨU}

1. Đặc điểm chung. Có tất cả 64 người bệnh trong nghiên cứu. Tuổi trung bình của nhóm đối tượng nghiên cứu là $32,98 \pm 12,87$ tuổi. Nhóm tuổi nhiều người bệnh nhất là từ 20 tuổi đến dưới 60 tuổi là 57 trường hợp, chiếm 89\%. Nhóm bệnh nhân nam chiếm đa số với 79,7\%, bệnh nhẩn nữ chỉ có $20,3 \%(p<0,05)$.

Nguyên nhân gây tổn thương thần kinh: vô căn chiếm $26,6 \%$, liên quan tới kết hợp xương chiếm $26,6 \%$, vết thương $31,3 \%$, chấn thương $12,5 \%$, và có 2 trường hợp sau chó cắn và mổ u xơ thân kinh.

Thời gian từ khi có dấu hiệu lâm sàng đến khi khám điện chẩn cơ: trong 10 ngày đâu có $28,1 \%, 11-20$ ngày chiếm $10,9 \%$, từ $21-30$ ngày chiếm $42,2 \%$ và chỉ có $18,8 \%$ khám sau 1 tháng đến 3 tháng.

2. Đặc điểm lâm sàng, điện chẩn cơ. Tổn thương hai nhánh tận thần kinh quay chiếm 6,3\%, tổn thương một nhánh tận chiếm 15,6\%, tổn thương đơn dây thần kinh quay chiếm $53,1 \%$ và tổn thương thần kinh quay phối hợp với dây thần kinh khác chiếm $25 \%$.

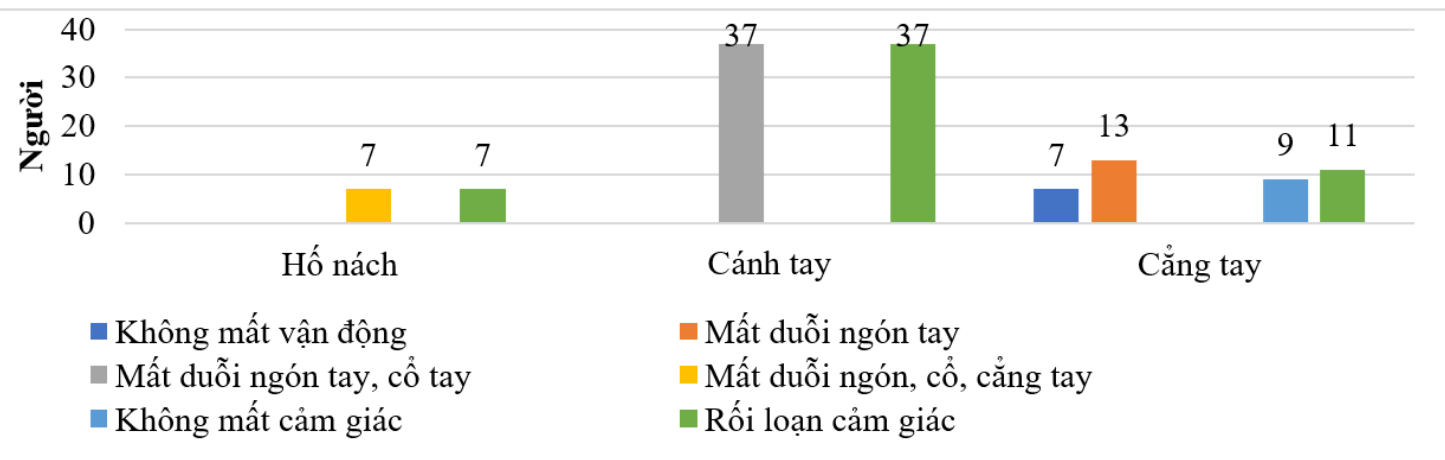

Biểu đồ 1. Phân bố triệu chứng vận động và cảm giác theo vị trí tổn thương

Nhận xét: Tổn thương tại hố nách có 7 trường hợp, chiếm $10,9 \%$ : có rối loạn cảm giác và mất duỗi ngón, cổ, cẳng tay. Tồn thương tại cánh tay có 37 trường hợp, chiếm $57,8 \%$ : có rối loạn cảm giác và mất duỗi ngón, cổ tay. Tổn thương tại cẳng tay có 20 trường hợp, chiếm 31,3\%: 10,9\% không mất vận động, 14,1\% không có triệu chứng cảm giác. 


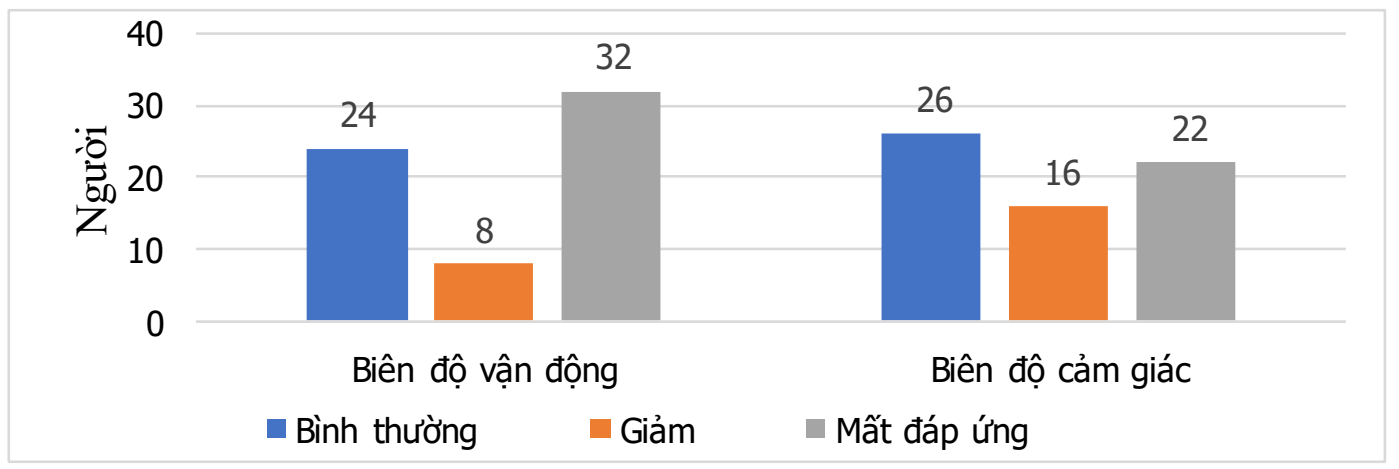

Biểu đồ 2. Kết quả ghi dẫn truyền thần kinh vận động và cảm giác

Nhận xét: Biên độ đáp ứng vận động bình thường ở 24 trường hợp, chiếm 37,5\%, giảm ở $12,5 \%$ và mất đáp ứng ở $50 \%$ số ca. Biên độ đáp ứng cảm giác bình thường ở 40,6\%, giảm ở $25 \%$ và mất đáp ứng ở $34,4 \%$ số ca.

Có $29,7 \%$ số ca có hiện tượng nghẽn dẫn truyền thần kinh, 70,3\% số ca không có nghẽn dẫn truyền thần kinh.

Không có điện thế tự phát ở 29,7\% trường hợp, mức độ $1+$ có $7,8 \%$, mức $2+$ có $4,7 \%$, mức 3+ có 42,2\%, mức 4+ có $15,6 \%$.

3. Mối liên quan giữa các yếu tố nguy cơ với kết quả sau 6 tháng

Có 34,4\% số trường hợp phục hồi hoàn toàn chức năng thân kinh quay, 37,5\% số ca hồi phục không hoàn toàn và $28,1 \%$ không phục hồi.

\begin{tabular}{|c|c|c|c|c|}
\hline & $\begin{array}{c}\text { Khỏi hoàn } \\
\text { toàn }\end{array}$ & Đช̃ & $\begin{array}{c}\text { Không } \\
\text { khỏi }\end{array}$ & p \\
\hline $\begin{array}{l}<1 \\
\text { tháng }\end{array}$ & $\begin{array}{c}11 \\
44 \% \\
\end{array}$ & $\begin{array}{c}11 \\
44 \% \\
\end{array}$ & $\begin{array}{c}3 \\
12 \% \\
\end{array}$ & \multirow{3}{*}{$\stackrel{>}{>05}$} \\
\hline $\begin{array}{l}>1 \\
\text { tháng }\end{array}$ & $\begin{array}{c}11 \\
28,2 \%\end{array}$ & $\begin{array}{c}13 \\
33,3 \%\end{array}$ & $\begin{array}{c}15 \\
38,5 \%\end{array}$ & \\
\hline Tổng & $\begin{array}{c}22 \\
34,4 \% \\
\end{array}$ & $\begin{array}{c}24 \\
37,5 \% \\
\end{array}$ & $\begin{array}{c}18 \\
28,1 \% \\
\end{array}$ & \\
\hline
\end{tabular}

Nhận xét: Có $88 \%$ trường hợp phục hôi thân kinh ở nhóm đối tượng khám và điều trị trong tháng đâu tiên, $12 \%$ không hồi phục. Ở nhóm đối tượng sau 1 tháng tỷ lệ này là $61,5 \%$ và $38,5 \%$, có giảm so với nhóm trên nhưng chưa có ý nghĩa thống kê ( $p>0,05)$.

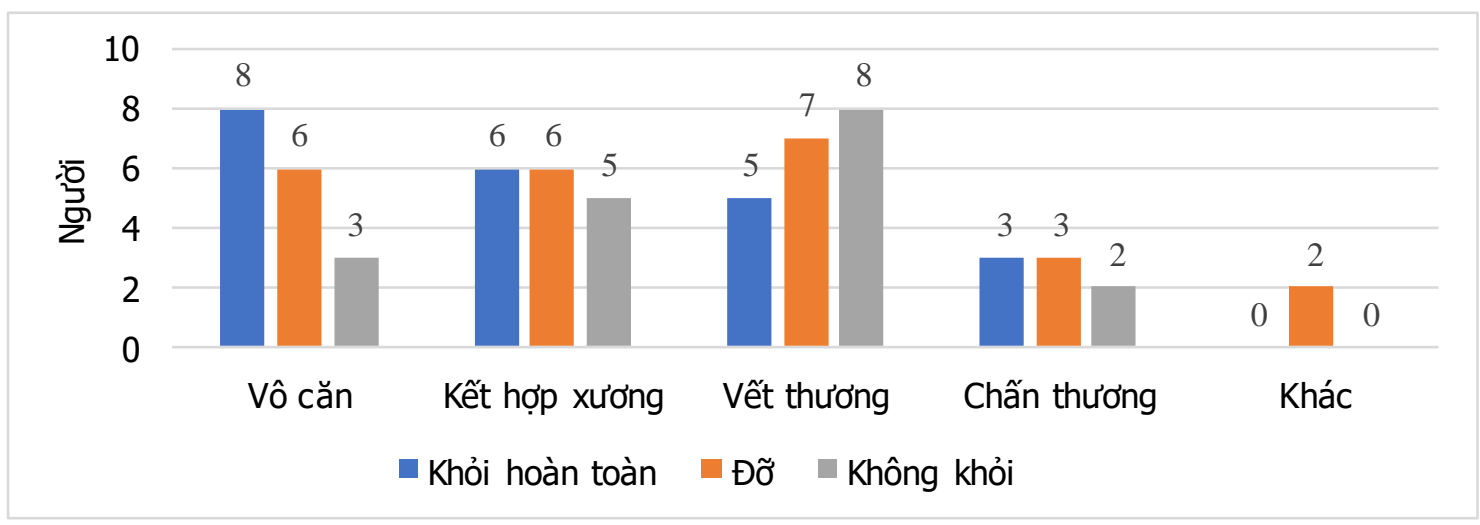

Biểu đồ 3. Kêt quả điều trị theo từng nguyên nhân

Nhận xét: Tỷ lệ phục hồi thân kinh ở nhóm nguyên nhân vô căn là cao nhất $82,4 \%$, do chấn thương phục hôi $60 \%$, liên quan kết hợp xương phục hồi $70,6 \%$, do vết thương phục hồi $60 \%$. Tỷ lệ này khác biệt không có ý nghĩa thống kê (p>0,05).

Bảng 2. Môi liên quan giữa điện chân cơ với kêt quá điều trị

\begin{tabular}{|c|c|c|c|c|}
\hline & $\begin{array}{c}\text { Khỏi hoàn } \\
\text { toàn }\end{array}$ & Đõ & $\begin{array}{c}\text { Không } \\
\text { khỏi }\end{array}$ & $\mathbf{p}$ \\
\hline
\end{tabular}

\begin{tabular}{|c|c|c|c|c|}
\hline \multirow{2}{*}{ Không } & 12 & 16 & 16 & \multirow{2}{*}{$<$} \\
\cline { 1 - 4 } Có & $27,3 \%$ & $36,4 \%$ & $36,4 \%$ & 0 \\
& 10 & 8 & 1 & 0,05 \\
\hline
\end{tabular}

Nhânn xét: Nhóm nghẽn dẫn truyền thân kinh phục hôi tới 94,7\%; nhóm không nghẽn dẫn truyền thần kinh phục hồi $63,7 \%$. Sự khác biệt này có ý nghĩa thống kê $p<0,05$.

IV. BÀN LUẬN

Có tất cả 64 người bệnh với tuổi trung bình là 
32,98 12,87 tuổi. Nhóm tuổi từ 20 tuổi đến dưới 60 tuổi chiếm $89 \%$. Nhóm bệnh nhân nam chiếm đa số với $79,7 \%$. Đây là nhóm đối tượng lao động chính trong xã hội nên điều trị tốt cho người bệnh vừa hạn chế tối đa các gánh nặng cho xã hội mà còn giúp người bệnh lao động sớm. Kết quả này tương tự nghiên cứu của các tác giả trong nước và trên thế giới (bảng 4.1).

Bảng 3. So sánh phân bố giới tính ở các nghiên cứu

\begin{tabular}{|c|c|c|c|}
\hline Tác giả/ Năm & $\mathbf{n}$ & $\begin{array}{c}\text { Nam } \\
\text { \% }\end{array}$ & $\begin{array}{c}\text { Nữ } \\
\text { \% }\end{array}$ \\
\hline Võ Đôn/2018[5] & 189 & 83,6 & 16,4 \\
\hline Szylejko A/2015 [6] & 202 & 90 & 10 \\
\hline
\end{tabular}

Nguyên nhân gây tốn thương thần kinh: vô căn chiếm $26,6 \%$, liên quan tới kết hợp xương chiếm $26,6 \%$, vết thương $31,3 \%$, chấn thương $12,5 \%$, và có 2 trường hợp sau chó cắn và mổ u xơ thần kinh. Nguyên nhân tổn thương dây thần kinh quay rất đa dạng, chử yếu liên quan trực tiếp đến cấu trúc giải phẫu đi gần xương và chiều dài của dây thần kinh quay.

Tổn thương thần kinh tại cẳng tay chiếm $31,3 \%$, tại cánh tay chiếm $57,8 \%$ và tại hố nách chiếm 10,9\%. Tổn thương tại cánh tay chiếm phần lớn và được giải thích bởi giải phẫu dây thần kinh quay đi sát với xương cánh tay nên nguy cơ có tổn thương cao hơn so với các vị trí khác. Lâm sàng tổn thương tại hố nách có 7 trường hợp, chiếm 10,9\%: có rối loạn cảm giác và mất duối ngón, cố, cẳng tay. Tổn thương tại cánh tay có 37 trường hợp, chiếm $57,8 \%$ : có rối loạn cảm giác và mất duỗi ngón, cổ tay. Tổn thương tại cẳng tay có 20 trường hợp, chiếm 31,3\%: 10,9\% không mất vận động, 14,1\% không có triệu chứng cảm giác. Dây thần kinh quay đi dài và phân nhiều nhánh chi phối cơ cánh - cẳng tay cũng như cảm giác các vùng cánh - cẳng - bàn tay, việc này tạo ra sự đa dạng về mặt triệu chứng lâm sàng tương ứng với sự đa dạng của vị trí tổn thương dây thần kinh.

Triẹu chứng trên dẫn truyền thần kinh: biên độ đáp ứng vận động bình thường ở 37,5\% trường hợp, giảm ở $12,5 \%$ và mất đáp ứng ở $50 \%$ số ca. Biên độ đáp ứng cảm giác bình thường ở $40,6 \%$, giảm ở $25 \%$ và mất đáp ứng ở $34,4 \%$ số ca. Có $29,7 \%$ số ca có hiện tượng nghẽn dẫn truyền thần kinh, $70,3 \%$ số ca khồng có nghẽn dẫn truyền thần kinh. Các thông số dẫn truyền thần kinh phụ thuộc vào thời gian tổn thương (thời gian để thoái hoá ngược Wallerian xảy ra), loại tổn thương (chèn ép, cắt ...) nên sẽ có sự thay đổi, ví dụ: giai đoạn sớm của tổn thương, biên độ đáp ứng vận động và cảm giác còn ở trong giới hạn bình thường và có hiện tượng nghẽn dẫn truyền qua vị trí tổn thương, nhưng theo thời gian, hiện tượng thoái hoá sợi trục xảy ra làm mất hiện tượng nghẽn dẫn truyền đồng thời biên độ đáp ứng vận động và cảm giác sẽ giảm hoặc mất. Điều này yều cầu bác sĩ chẩn đoán điện thần kinh phải có kiến thức về giải phẫu, sinh lý, bệnh học và điện chẩn cơ để đưa ra phương pháp thăm khám và kết luận phù hợp từng giai đoạn[7].

Triệu chứng trên điện cơ đồ dùng điện cực kim: không có điện thế tự phát ở $29,7 \%$ trường hợp, mức độ $1+$ có $7,8 \%$, mức $2+$ có $4,7 \%$, mức $3+42,2 \%$, mức $4+$ là $15,6 \%$. Trong giai đoạn sớm của tổn thương, hình thái đơn vị vận động chưa có biến đổi nên trong nghiên cứu này chúng tôi không đề cập tới. Điện thế tự phát là hiện tượng điện xuất hiện khi cơ ở trạng thái nghỉ, phản ánh sự bất thường của màng tế bào sợi cơ do sự mất chi phối thần kinh, nên cũng xuất hiện phụ thuộc nhiều vào thời gian và hình thái tổn thương, tạo nên sự đa dạng về mức độ.

Có $34,4 \%$ số trường hợp phục hồi hoàn toàn chức năng thần kinh quay, $37,5 \%$ số ca hồi phục không hoàn toàn và $28,1 \%$ không phục hồi. Tỷ lệ có phục hồi chức năng thần kinh là $71,9 \%$, tỷ lể này tương đương với nghiên cứu của Shao YC và cộng sự năm 2005[3]. Điều này càng có cơ sở để khẳng định tổn thương dây thần kinh quay có tiên lượng phục hồi tốt và mức độ tổn thương chủ yếu là mất thực dụng thần kinh và tổn thương sợi trục. Có $88 \%$ trường hợp phục hồi thần kinh ở nhóm đối tượng khám và điều trị trong tháng đầu tiên, 12\% không hồi phục. Điều này đã được chứng minh qua kết quả nghiên cứu Shwab TR và cộng sự 2018[8], Khi có tới $90 \%$, thậm chí $100 \%$ các trường hợp ở nhóm đối tượng mất thực dụng thần kinh sẽ phục hồi thần kinh sau 2-3 tháng. Ở nhóm đối tượng sau 1 tháng tỷ lệ này là $61,5 \%$ và $38,5 \%$, có giảm so với nhóm trển nhưng chưa có ý nghĩa.

Tỷ lệ phục hồi thần kinh ở nhóm nguyên nhân vô căn là cao nhất $82,4 \%$, do chấn thương phục hồi $60 \%$, liên quan kết hợp xương phục hồi $70,6 \%$, do vết thương phục hồi $60 \%$. Nhóm nghẽn dẫn truyền thần kinh phục hồi tới 94,7\%; nhóm không nghẽn dẫn truyền thần kinh phục hồi $63,7 \%$. Có lẽ, nguyên nhân vô căn gây tổn thương chủ yếu kiểu mất thực dụng trong khi các hình thái khác gây tổn thương sợi trục và tổn thương thần kinh nên kết quả phục hồi có khác nhau, nên tiến hành khảo sát kĩ từng hình thái thương tổn trong những nghiên cứu lớn hơn để có cơ sở khẳng định. 


\section{KẾT LUẬN}

Triêu chứng lâm sàng và điên chẩn cơ trong tổn thương dây thân kinh quay rất đa dạng: 10,9\% không mất vận động, 14,1\% không mất cảm giác... phụ thuộc vào vị trí, thời gian và hình thái tổn thương. Dây thân kinh quay có tiên lượng phục hồi tốt $71,9 \%$, có liên quan tới thời gian phát hiện và điều trị, hình thái tổn thương và dấu hiệu trên điện chẩn cơ.

\section{TÀI LIẸU THAM KHẢO}

1. BumbasirevicM, PalibrkT, LesicA, và cộng sự (2016). Radial nerve palsy. EFORT Open $\operatorname{Rev}, \mathbf{1}(\mathbf{8}), 286-294$.

2. SeddonH. J.(1942). A Classification of Nerve Injuries. Br Med J,2(4260),237-9.

3. ShaoY. C, HarwoodP, GrotzM. R và cộng sự (2005). Radial nerve palsy associated with fractures of the shaft of the humerus: a systematic review. J Bone Joint Surg Br,87(12),1647-52.
4. HeB, ZhuZ, ZhuQ và cộng sự (2014). Factors predicting sensory and motor recovery after the repair of upper limb peripheral nerve injuries. Neural Regen Res, $9(6), 661-72$.

5. Võ Đôn, Nguyển Hữu Công (2018). Đặc điểm điên sinh lỳ trong chấn thương thần kinh ngoại biển. Y học TP. Hồ Chí Minh,1(Phụ bản tập 22),211-216.

6. SzyłejkoA., Bielecki, M , Terlikowski, R. (2015). Epidemiology of upper limb peripheral nerve injuries in the material collected in the Department of Orthopedics and Traumatology Medical University of Bialystok. Progress in Health Sciences,5(1),130-137.

7. LaulanJ. (2019). High radial nerve palsy. Hand Surg Rehabil,38(1),2-13.

8. SchwabT. R,StillhardP. F, Schiblis và công sư (2018). Radial nerve palsy in humeral shaft fractures with internal fixation: analysis of management and outcome. Eur J Trauma Emerg Surg, 44(2), 235-243.

\section{NGHIÊN CỨU CHỈ SỐ SỨC CĂNG DỌC THẤT TRÁI BẰNG SIÊU ÂM ĐÁNH DẤU MÔ Cơ TIM Ở BỆNH NHÂN MẮC BỆNH MẠCH VÀNH MẠN TÍNH}

\section{TÓM TẮT}

Mục tiêu: Đánh giá chỉ số sức căng dọc thất trái (Left ventricular global longitudinal strain - LVGLS) và mối liên quan với một số chỉ số siêu âm tim 2D ở người mắc bệnh mạch vành mạn tính. Đối tượng và phương pháp: 43 bệnh nhân bệnh mạch vành mạn tínhđã được chẩn đoán xác định bằng chụp mạch vành qua đường ống thông, sau đó được thực hiện siêu âm tim, phân tích kết quả đánh dấu mô bằng phần mềm QLAB version 9.0. Kết quả: Giá trị LVGLS trung bình của nhóm nghiên cứu là $-15,69 \pm 4,07 \%$. Với mức hẹp mạch vành đáng kể ( $\geq 70 \%)$ được xác định bằng chụp mạch vành, giá trị cut-off của LVGLS $=-17,95 \%$, độ nhạy 85\%, độ đặc hiệu 54,55\% (p < $0,05)$; LVGLS có mối liên quan với giảm vận động vùng $(p<0,05)$ và có mối tương quan nghịchvới $E F$ Simpson Biplane trên siêu âm tim 2D $(r=-0.46, p<$ $0,05)$. Kết luận: Sức căng dọc thất trái trên siêu âm đánh dấu mô cơ tim giảm ở người mắc BMVMT, giá trị cut-off để tiên lượng hẹp mạch vành đáng kể là $17,95 \%$, có mối liển quan với giảm vận động vùng và tương quan nghịch với phân suất tống máu EF Simpson Biplane trên siêu âm tim 2D.

Tư khóa: Bệnh mạch vành mạn tính, Siêu âm đánh dấu mô cơ tim, chỉ số sức căng dọc thất trái.

*Viên Y học Phòng không - Không quân **Bệnh viện Quân y 103

Chịu trách nhiệm chính: Đặng Đình Đôn Email: donlampart1301@gmail.com Ngày nhận bài: 3/5/2021

Ngày phản biện khoa học: 4/6/2021

Ngày duyệt bài: 16/6/2021

\section{SUMMARY}

ELEVATING LEFT VENTRICULAR GLOBAL LONGITUDINAL STRAIN(LVGLS) INDEX ON ECHOCARDIOGRAPHY 2D IN PATIENTS

\section{WITH CHRONIC CORONARY DISEASE}

Purposes: To elevate left ventricular global longitudinal strain (LVGLS) index and the relationship with several indexes on echocardiography 2D in patients with chronic coronary disease. Subjects and methods: Including 43 patients with chronic coronary disease diagnosed by angiography, then performed echocardiography, analysis results ofspeckle trackingechocardigraphy by QLAB version 9.0 software. Results: Mean of LVGLS is $-15,69 \pm 4,07 \%$. With level of significant coronary stenosis ( $\geq 70 \%)$ is confirmed by angrography, cut-off value of LVGLS is $17,95 \%$, the sensitivity is $85,71 \%$, the specificity is $54.55 \%(p<0,05)$. LVGLS has the relationship with regional hypokinesis $(p<0,05)$ and the inverse correlation with EF simpson biplane on echocardiography $2 D(r=-$ $0.46 p<0,05)$. Conclusions: Left ventricular global longitudinal strain on speckle tracking echocardigraphy reduce in patients with chronic coronary disease. Its cut-off value to prognosis significant coronary stenosis is $-17,95 \%$, it has the relationship with regional hypokinesis and the inverse correlation with ejection fraction simson biplane on echocardiography 2D.

Key word: Chronic coronary disease; speckle tracking echocardigraphy; left ventricular global longitudinal strain. 